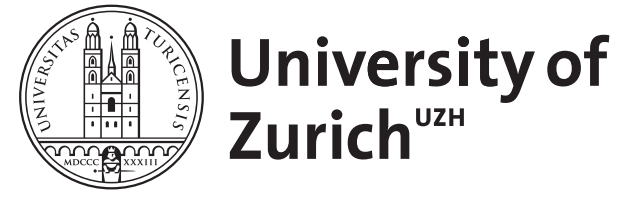

\title{
Heterogeneous outside options in contests
}

Grossmann, Martin ; Dietl, Helmut

DOI: https://doi.org/10.1016/j.ejpoleco.2014.09.006

Posted at the Zurich Open Repository and Archive, University of Zurich ZORA URL: https://doi.org/10.5167/uzh-109948

Journal Article

Accepted Version

Originally published at:

Grossmann, Martin; Dietl, Helmut (2015). Heterogeneous outside options in contests. European Journal of Political Economy, 37:280-287.

DOI: https://doi.org/10.1016/j.ejpoleco.2014.09.006 


\title{
Heterogeneous outside options in contests
}

\author{
Martin Grossmann $^{a, b *}$, Helmut Dietl ${ }^{a}$
}

\begin{abstract}
This article describes a large number of contestants with high and low levels of talent who individually decide to enter a contest or take their heterogeneous outside options. We derive a critical condition for which only high types, only low types or both types participate in the contest. If a contest organizer is worried about the type participating in the contest, then he/she should provide a contest with low noise to attract high types. However, if a contest organizer's objective is to maximize the individual effort, he/she will not necessarily prefer to have the high types in the contest.

${ }^{a}$ Department of Business Administration, University of Zurich, Plattenstrasse 14, 8032 Zurich, Switzerland

${ }^{b}$ School of Business, Lucerne University of Applied Sciences and Arts, Zentralstrasse 9, 6002 Lucerne, Switzerland

* Corresponding author: tel.: +41 44634 5315; fax +41 44634 5329. e-mail address:

martin.grossmann@business.uzh.ch
\end{abstract}

\section{Introduction}

In this paper, we analyze how the value of an exogenous outside option determines the participation of competitors in an uncertain contest. Moreover, we determine how the value of the outside option affects the competitors' effort choice. Generally, competitors elicit effort in contests in order to increase their probability of receiving a contest prize. ${ }^{1}$ In academia, for instance, Ph.D. students learn and research for several years, striving for a possible professorship in the future. Their immediate outside opportunity is employment in the private or public sector. While the contest literature mainly considers situations in which a specific number of contestants participate in the contest, we will focus on a preceding decision in this article: should a competitor enter a contest or should he/she prefer an outside option? We will shed light on the value of an outside option in a standard Tullock contest, assuming that two different types of competitors exist. There is a large number of highly talented contestants and simultaneously a large number of low-talented contestants. Contestants with high (low) ability have small (large) effort costs.

In the contest literature, several articles consider the effect of symmetric outside options in contests (e.g., Corcoran, 1984; Hillman and Katz, 1984; Appelbaum and Katz, 1986; Appelbaum and Katz, 1987; Fullerton and McAfee, 1999; Moldovanu and Sela, 2001; Fu and Lu, 2010; Morgan et al., 2012). ${ }^{2}$ Surprisingly, none of these papers analyze the effect of asymmetric outside options. ${ }^{3} \mathrm{Fu}$ and $\mathrm{Lu}(2010)$, for instance, conclude that

\footnotetext{
${ }^{1}$ For a survey of the contest literature, see Konrad (2009) and Long (2013).

${ }^{2}$ Some of these contributions analyze the effect of a symmetric entry fee on contestants' behavior. Entry fees have a similar effect as outside options in contests. Moreover, note that Hillman and Katz (1984) introduce an elementary outside option in a rent-seeking contest. Contestants keep their wealth if they do not participate in the contest.

${ }^{3}$ The effect of asymmetry in contests with respect to contestants' prize valuation, information or effort cost has been extensively analyzed in the literature (see, e.g., Nti, 1999; Hurley and Shogren, 1998; Nti, 2004; Szymanski and Valletti, 2005; Kräkel, 2007; Franke, 2012; Grossmann, 2014). A forthcoming survey of asymmetric rent-seeking contests will be provided by Dari-Mattiacci, Langlais, Lovat, and Parisi (2015).
} 
only two contestants should participate in the contest to maximize the total effort. However, they emphasize that their results depend on the assumption of symmetry. ${ }^{4}$ The purpose of this paper is to fill this gap by discussing the interaction of two kinds of heterogeneity in contestants' entry decision and effort choice as contestants are endowed with different talents and different outside options.

The main results are the following. (i) We derive a critical condition determining the type of contestant who enters the contest, and (ii) we show that the individual effort is surprisingly independent of the contest prize. The reason for this result is that a greater prize would lure more competitors into the contest, thus destroying any further effort incentives. (iii) A larger value of an outside option increases the individual effort. Thus, there is a spillover effect of the outside option on competitors' behavior in a contest. The model can explain a self-reinforcing mechanism of high-performing economic environments and regions. Great alternative market opportunities increase the competitors' individual effort in a contest. (iv) If a contest organizer is worried about the type participating in the contest, then he/she should provide a contest with low noise to attract high types. (v) If a contest organizer's objective is to maximize the individual effort, he/she will not necessarily prefer to have the high types in the contest. ${ }^{5}$

The remainder of this article is structured as follows: Section 2 introduces the assumptions of the model and Section 3 presents the results, while Section 4 summarizes the main results and concludes the paper.

\section{Model}

In this contest, two types of contestants exist, called $H$ and $L$. There is a measure $m$ of type $H$ contestants with high talent levels and a measure $n$ of type $L$ contestants with low talent levels. All the contestants are risk-neutral and maximize their expected profits. If a contestant participates in the contest, then he/she can invest $x$ in order to increase the probability of winning an exogenous prize $V$. The relative investments of all the contestants determine the winning probability. The contest success function (CSF) for the high-type contestant $i$ who chooses effort $x_{H}(i)$ is

$$
p\left(x_{H}(i), X\right)=\frac{x_{H}(i)}{X}
$$

where $X \equiv \int_{0}^{m} x_{H}(i) d i+\int_{0}^{n} x_{L}(j) d j$ represents the aggregate effort in the contest. ${ }^{6}$ If all the high-type contestants participating in the contest choose the same effort $\hat{x}$ then $\int_{0}^{m} x_{H}(i) d i=\int_{0}^{m} \hat{x} d i=\hat{x} \int_{0}^{m} d i=$ $\hat{x} m$. Similarly, if all the low types choose the same effort $\tilde{x}$, then $\int_{0}^{n} x_{L}(j) d j=\int_{0}^{n} \tilde{x} d j=\tilde{x} \int_{0}^{n} d j=\tilde{x} n$. Symmetrically, the CSF for the low-type contestant $j$ who chooses effort $x_{L}(j)$ is $p\left(x_{L}(j), X\right)=x_{L}(j) / X$.

The difference in the ability between the $H$ and the $L$ types is modeled with the assumption of different effort cost functions:

$$
C_{H}\left(x_{H}(i)\right)=c_{H} \cdot x_{H}(i)^{\mu} \text { and } C_{L}\left(x_{L}(j)\right)=c_{L} \cdot x_{L}(j)^{\mu} \text { with } c_{L}>c_{H} \text { and } \mu>1
$$

Since $c_{L}>c_{H}$, a contestant with low ability has higher marginal costs than a contestant with high ability

\footnotetext{
${ }^{4}$ The authors invite researchers to explore the effect of heterogeneity on entry in contests (p.88).

${ }^{5}$ We will show that the interaction of the two different sources of heterogeneity, i.e., heterogeneous types and heterogeneous outside options, are responsible for obtaining results (i), (iv) and (v).

${ }^{6}$ Instead of the continuous representation of the aggregate, we could also assume a case with finitely many discrete contestants such that the aggregate is defined as $X \equiv \sum_{i=1}^{m} x_{H}(i)+\sum_{j=1}^{n} x_{L}(j)$. Since the continuous case will be more tractable to derive the critical amount of contestants who enter the contest in equilibrium, we henceforth use the continuous representation.
} 
for a given effort level. The cost functions have a constant cost elasticity of $\mu$.

The two types of contestants also differ with respect to their outside option. They have an exogenously given outside option of value $w_{k}>0$ for $k \in\{H, L\}$ and $w_{L} \gtreqless w_{H}$. Therefore, in comparison with the low types, the high types can have an advantage or a disadvantage regarding their outside option. ${ }^{7}$ A contestant only participates in the contest if the expected profit is not less than the value of the outside option.

If the high-type contestant $i$ participates in the contest, the expected profit is:

$$
\pi_{H}(i)=\frac{x_{H}(i)}{X} V-c_{H} \cdot x_{H}(i)^{\mu}
$$

Symmetrically, the expected profit of the low-type contestant $j$ is:

$$
\pi_{L}(j)=\frac{x_{L}(j)}{X} V-c_{L} \cdot x_{L}(j)^{\mu}
$$

In appendix A, we reformulate the profit function and show that the parameter $\mu$ can also be interpreted as the sensitivity of the CSF. A larger value of $\mu$ means that the sensitivity of the CSF decreases and the contest is noisier. As $\mu$ converges to infinity, the CSF becomes independent of the contestants' investment. Therefore, $\mu$ is also interpreted as the contest noise in the model. ${ }^{8}$

\section{Aggregate-taking behavior}

We assume the presence of aggregate-taking behavior (ATB) in the model. ${ }^{9}$ ATB means that the contestants choose their strategy through taking the aggregate effort $X$ as given. The reason for this assumption is as follows. Firstly, if many contestants participate in the contest, then it makes sense to assume that each competitor does not take into account the effort of each opponent individually. Instead, a contestant rather evaluates the aggregate effort in the contest. Secondly, we show in Appendix B that the ATB equilibrium converges to the Nash equilibrium for a large number of players. As there is a large number of contestants in our model, we claim that our ATB equilibrium is a good approximation of the Nash equilibrium. Thirdly, the assumption of ATB implies high tractability of the model. Due to ATB, we are able to analyze a general model with two different kinds of heterogeneity and a general class of effort cost functions. As Appelbaum and Katz (1986) and Fu and Lu (2010) do not apply ATB, their analysis is restricted to a completely symmetric contest with a specific effort cost function.

\footnotetext{
${ }^{7}$ This assumption makes sense as a high level of talent in one field does not necessarily mean a high level of talent in other fields.

${ }^{8}$ In a perfectly discriminating contest without noise (all-pay auction), the highest bidder wins the contest. Hillman and Samet (1987) analyzed entry in all-pay auctions for a finite number of symmetric contestants. Contestants have to pay a minimum outlay in order to participate in the contest. Hillman and Samet show that the expected aggregate effort is less than the prize in equilibrium with mixed strategies. But the expected aggregate effort equals the expected prize such that full rent dissipation results on average.

${ }^{9}$ See e.g. Alós-Ferrer and Ania (2005) and Grossmann et al. (2012) for games with ATB. Possajennikov (2003) illustrates that the ATB in rent-seeking games is evolutionarily stable. Jensen (2010) analyzes the best-reply potentials in aggregative games.
} 


\section{Results}

\subsection{General results}

With the application of ATB, therefore taking $X$ as given, contestant $i$ 's first-order condition as a high type is: ${ }^{10}$

$$
\frac{\partial \pi_{H}(i)}{\partial x_{H}(i)}=\frac{V}{X}-\mu c_{H} x_{H}(i)^{\mu-1}=0
$$

Symmetrically, contestant $j$ 's first-order condition as a low type is:

$$
\frac{\partial \pi_{L}(j)}{\partial x_{L}(j)}=\frac{V}{X}-\mu c_{L} x_{L}(j)^{\mu-1}=0
$$

In the following discussion, we concentrate on the symmetric equilibrium within the two types. This means that high-type contestants choose the same effort in equilibrium if they participate in the contest. Similarly, low-type contestants entering the contest choose the same effort in equilibrium. ${ }^{11}$ Combining the two first-order conditions, we obtain $x_{H}(i) / x_{L}(j)=\left(c_{L} / c_{H}\right)^{\frac{1}{\mu-1}}$. Using this condition, the first-order conditions (3) and (4) and the profit functions (1) and (2), and applying the symmetry assumption within the types, we obtain the following lemma: ${ }^{12}$

Lemma 1 If $m$ high types and $n$ low types participate in the contest,

(i) the contestants' efforts are $\left.x_{H}(i)=\left(\frac{V\left(c_{L} \frac{1}{\mu-1}\right.}{\mu c_{H}\left(m\left(c_{L}\right)^{\frac{1}{\mu-1}}+n\left(c_{H}\right)^{\frac{1}{\mu-1}}\right.}\right)\right)^{\frac{1}{\mu}}$ and $x_{L}(j)=\left(\frac{V\left(c_{H}\right)^{\frac{1}{\mu-1}}}{\mu c_{L}\left(m\left(c_{L}\right)^{\frac{1}{\mu-1}}+n\left(c_{H}\right)^{\frac{1}{\mu-1}}\right)}\right)^{\frac{1}{\mu}}$

(ii) the contestants' profits are $\pi_{H}(i)=\frac{\mu-1}{\mu} \frac{V\left(c_{L}\right)^{\frac{1}{\mu-1}}}{m\left(c_{L}\right)^{\frac{1}{\mu-1}}+n\left(c_{H}\right)^{\frac{1}{\mu-1}}}$ and $\pi_{L}(j)=\frac{\mu-1}{\mu} \frac{V\left(c_{H}\right)^{\frac{1}{\mu-1}}}{m\left(c_{L}\right)^{\frac{1}{\mu-1}}+n\left(c_{H}\right)^{\frac{1}{\mu-1}}}$.

A high type chooses greater effort and receives more expected profit than a low type if he/she participates in the contest. Note that the effort is independent of the outside options but a greater contest prize increases the effort. We will show that both results are based on the assumption of exogenous participation of contestants. As participation in the contest is endogenous, we next calculate the number and type of players who enter the contest in equilibrium. Contestants participate in the contest if their expected profit is not less than the value of the outside option. We have to differentiate between the three cases presented in Propositions (1), (3) and (4).

If $\pi(i)^{H}>w_{H}$ or $\pi(j)^{L}>w_{L}$, then more low- and high-type contestants enter the contest. Therefore, the two conditions $\pi_{H}^{*}(i) \leqslant w_{H}$ and $\pi_{L}^{*}(j) \leqslant w_{L}$ must hold in equilibrium. Suppose that $w_{H} / w_{L}<$ $\left(c_{L} / c_{H}\right)^{\frac{1}{\mu-1}}$ holds such that the high types' cost advantage is strictly larger than the outside option advantage/disadvantage. It immediately follows that $\pi_{H}^{*}(i) / \pi_{L}^{*}(j)>w_{H} / w_{L}$ holds in equilibrium. According to this inequality, it is easy to see that only the high types enter the contest until the last participant is indifferent between participating in the contest and choosing the outside option. Thus, $\pi_{H}^{*}(i)=w_{H}$ and

\footnotetext{
${ }^{10}$ The difference between ATB and the best response (BR) is as follows: contestants do not take into account their direct impact on the aggregate in the case of ATB. In the case of BR, however, this effect is incorporated. In equilibrium, $X \equiv$ $\int_{0}^{m} x_{H}(i) d i+\int_{0}^{n} x_{L}(j) d j$ holds in both cases.

${ }^{11} \mathrm{Ex}$ ante, is is not clear whether only symmetric equilibria exist. Chowdhury and Sheremeta (2011), for instance, find asymmetric equilibria in a symmetric contest with spillovers.

${ }^{12}$ Note that the second-order conditions are satisfied.
} 
therefore $\pi^{*}(j)^{L}<w_{L}$ hold in equilibrium such that no low type has an incentive to enter the contest. Combining these findings with the results from Lemma (1), we obtain the following proposition:

Proposition 1 If $\frac{w_{H}}{w_{L}}<\left(\frac{c_{L}}{c_{H}}\right)^{\frac{1}{\mu-1}}$, then

(i) the number of participating contestants is $m^{*}=\frac{\mu-1}{\mu} \frac{V}{w_{H}}$ and $n^{*}=0$,

(ii) the high types" effort in the contest is $x_{H}^{*}(i)=\left(\frac{1}{\mu-1} \frac{w_{H}}{c_{H}}\right)^{\frac{1}{\mu}}$ and

(iii) the aggregate effort in the contest is $m^{*} x_{H}^{*}(i)=\frac{V}{\mu c_{H}}\left(\frac{(\mu-1) c_{H}}{w_{H}}\right)^{\frac{\mu-1}{\mu}}$ in equilibrium.

If the cost advantage overcompensates for the outside option's advantage/disadvantage, then only high types enter the contest according to part (i) of Proposition (1). Low types prefer their outside option since this contest is highly competitive with the presence of the much more talented high types. In Proposition (2), we derive some interesting comparative statics with respect to the equilibrium derived in Proposition (1).

Proposition 2 If $\frac{w_{H}}{w_{L}}<\left(\frac{c_{L}}{c_{H}}\right)^{\frac{1}{\mu-1}}$, then

(i) a greater contest prize $V$ or a lower value of the outside option $w_{H}$ increases the number of high types participating in the contest,

(ii) a greater value of the outside option $w_{H}$ surprisingly increases the high types' individual effort but, simultaneously, the high types' individual effort is independent of the contest prize $V$ and

(iii) a greater contest prize $V$ or a lower value of the outside option $w_{H}$ increases the aggregate effort in equilibrium.

Table 1 sums up the comparative statics derived in Proposition (2). The results of part (i) of Proposition (2) are intuitive. For a given number of participants, a greater prize increases the expected profits such that more contestants participate in the contest. If the value of the outside option decreases, the contest becomes more attractive and more contestants enter the contest.

According to part (ii), a larger value of the outside option surprisingly increases the high types' individual effort but, simultaneously, the high types' individual effort is independent of the contest prize. ${ }^{13}$ A larger contest prize has two effects that cancel each other out. Firstly, a larger prize directly increases the marginal revenue of effort. However, secondly, the larger prize also increases the number of participants in the contest such that the marginal revenue of effort decreases. Thus, a contest organizer should take into account that a larger prize would lure more competitors into the contest and oppress the incentives for additional individual effort. On the other hand, a greater outside option decreases the number of participating contestants such that the effort incentives increase in equilibrium. We conclude that great opportunities in economies can have positive spillover effects on other markets and competitions. Therefore, economies with diversified and strong markets benefit from each other. Strong markets make a contest more attractive as the contest becomes less crowded such that the competitors' individual effort incentives are greater. Applying the model's result to the firm level instead of the whole economy, we can argue that an employer may have an incentive to foster off-the-job training of his/her talented employees to some extent, even if this education only marginally improves their on-the-job skills. This training increases the employees' value on the job market (their outside

\footnotetext{
${ }^{13}$ In Lemma (1), we have shown that the effort is independent of the outside option but increases for a greater contest prize if the number of contestants is exogenously given. We conclude that the endogeneity of the contestants strongly affects the effort.
} 
option), but it simultaneously increases the effort incentives in the present job to be promoted to a higher position.

Part (iii) of Proposition (2), however, qualifies this result since the aggregate effort decreases with the value of the outside option. The lower participation overcompensates for the higher individual effort in the aggregate. We therefore conclude that the optimal heterogeneity with respect to the outside options depends on the organizer's objective.

\section{Table 1}

Comparative Statics for Proposition 1.

\begin{tabular}{|c|c|c|c|}
\hline \hline & $m^{*}$ & $x_{H}^{*}(i)$ & $m^{*} x_{H}^{*}(i)$ \\
\hline$V$ & + & no effect & + \\
\hline$w_{H}$ & - & + & - \\
\hline
\end{tabular}

We continue our analysis with a situation in which the high types' cost advantage is smaller than the outside option advantage, viz., $w_{H} / w_{L}>\left(c_{L} / c_{H}\right)^{\frac{1}{\mu-1}}$. It is easy to see that only the low types enter the contest until the last participant is indifferent between participating in the contest and choosing the outside option. We conclude that $\pi_{L}^{*}(j)=w_{L}$ and therefore $\pi_{H}^{*}(i)<w_{H}$ hold in equilibrium and the high types prefer their outside option. The following proposition sums up the main results:

Proposition 3 If $w_{H} / w_{L}>\left(c_{L} / c_{H}\right)^{\frac{1}{\mu-1}}$, then

(i) the number of participating contestants is $n^{*}=\frac{(\mu-1) V}{\mu w_{L}}$ and $m^{*}=0$,

(ii) the low-type effort in the contest is $x_{L}^{*}(j)=\left(\frac{1}{\mu-1} \frac{w_{L}}{c_{L}}\right)^{\frac{1}{\mu}}$ and

(iii) the aggregate effort in the contest is $n^{*} x_{L}^{*}(j)=\frac{V}{\mu c_{L}}\left(\frac{(\mu-1) c_{L}}{w_{L}}\right)^{\frac{\mu-1}{\mu}}$

in equilibrium.

If the cost advantage is smaller than the outside option advantage, then only low types enter the contest according to part (i) of Proposition (3). The comparative statics of parts (i) to (iii) of Proposition (3) are analogous to Table 1 and Proposition (2), and therefore can be neglected. Propositions (1) and (3) have shown that the type of participating contestants depends on the critical condition $w_{H} / w_{L} \gtreqless\left(c_{L} / c_{H}\right)^{\frac{1}{\mu-1}}$. In subsection 3.2, we will discuss the comparative statics of this condition in detail.

Prior to this analysis, we will consider the knife-edge condition $w_{H} / w_{L}=\left(c_{L} / c_{H}\right)^{\frac{1}{\mu-1}}$.

Proposition 4 If $\frac{w_{H}}{w_{L}}=\left(\frac{c_{L}}{c_{H}}\right)^{\frac{1}{\mu-1}}$, multiple equilibria exist in which

(i) the number of participating low and high types is defined by the equation $m^{*}=\frac{(\mu-1) V}{\mu w_{H}}-\frac{w_{L}}{w_{H}} n^{*}$ with $m^{*} \geqslant 0$ and $n^{*} \geqslant 0$ and

(ii) the low-type effort is $x_{L}^{*}(j)=\left(\frac{V\left(c_{H}\right)^{\frac{1}{\mu-1}}}{\mu c_{L}\left(m^{*}\left(c_{L}\right)^{\frac{1}{\mu-1}}+n^{*}\left(c_{H}\right)^{\frac{1}{\mu-1}}\right)}\right)^{\frac{1}{\mu}}$ and the high-type effort is $x_{H}^{*}(i)=$ $\left(\frac{V\left(c_{L}\right)^{\frac{1}{\mu-1}}}{\mu c_{H}\left(m^{*}\left(c_{L}\right)^{\frac{1}{\mu-1}}+n^{*}\left(c_{H}\right)^{\frac{1}{\mu-1}}\right)}\right)^{\frac{1}{\mu}}$ in the contest.

According to part (i) of Proposition (4), an infinite number of mixed equilibria is possible in which both types potentially participate in the contest. The mixed equilibrium exists if the talent advantage equals the outside option advantage. The number of high types participating in the contest depends on the number of 
low types entering the contest and vice versa. Equation $m^{*}=(\mu-1) V /\left(\mu w_{H}\right)-\left(w_{L} / w_{H}\right) n^{*}$ with $m^{*} \geqslant 0$ and $n^{*} \geqslant 0$ defines all the possible equilibria. As both types may enter the contest if the knife-edge condition holds, it makes sense to analyze the competitive balance in equilibrium. The competitive balance $C B_{H, L}$ between the high and the low types in a contest is usually defined as $C B_{H, L} \equiv p\left(x_{H}(i), X\right) / p\left(x_{L}(j), X\right) .{ }^{14}$ If $C B_{H, L}=1$, then the contest is fully balanced. The contest is less balanced the further value $C B_{H, L}$ is from one. For an interior solution with $m^{*}>0$ and $n^{*}>0$, it is easy to show that $C B_{H, L}=\left(c_{L} / c_{H}\right)^{1 /(\mu-1)}>1$ holds in equilibrium. Thus, the high types always have a larger winning probability than the low types in the contest. However, $C B_{H, L}$ is a strictly decreasing convex function in $\mu$. Therefore, more contest noise decreases the value $C B_{H, L}$ such that the competitive balance between the two different types increases.

\subsection{Contest organizer's objective}

In this subsection, we discuss our main results derived in the last subsection from the contest organizer's perspective. A contest organizer might be interested in the quality of the participants, i.e., high types or low types, and the individual and aggregate efforts in the contest. First, we reconsider the entry decision of high and low types. Based on the entry decision, the consequences for individual and aggregate efforts are evaluated afterwards.

\section{Entry decision}

Entry depends on the critical condition

$$
w_{H} / w_{L} \lessgtr\left(c_{L} / c_{H}\right)^{\frac{1}{\mu-1}}
$$

derived in Propositions (1) and (3). The comparative statics of the critical condition (5) is as follows. Note that the right-hand side (RHS) is larger than one while the left-hand side (LHS) is smaller or larger than one. Therefore, if the high types have the same or a lower value of the outside option compared with the low types, then only the high types participate in the contest and the results from Proposition (1) hold. If the value of the outside option of the high types is larger than the value of the outside option of the low types, then the relative costs and the parameter $\mu$, i.e., the contest noise, are critical. It is obvious that a larger cost ratio $c_{L} / c_{H}$ increases the RHS of the critical condition, but a lower contest noise $\mu$ increases the RHS of the critical condition as well. Therefore, we obtain the following corollary:

Corollary 1 Ceteris paribus, only high (low) types enter the contest if the contest noise $\mu$ is low (high), the cost ratio $c_{L} / c_{H}$ is large (low) or the outside option ratio $w_{H} / w_{L}$ is low (high).

As the three critical terms interact with each other, we next describe two counterintuitive situations. (i) Suppose that the high types have a much larger outside option than the low types, i.e., $w_{H}>>w_{L}$, such that only low types seem to participate in the contest. If the contest noise is sufficiently low, then even a relatively low cost advantage leads to $w_{H} / w_{L}<\left(c_{L} / c_{H}\right)^{\frac{1}{\mu-1}}$ such that only high types enter the contest. The reason for this effect is as follows: for a given value of $m$ and $n$, a larger contest noise implies a lower difference in efforts between the high and the low types. It immediately follows that the differences in profits decrease as well. Thus, a larger contest noise decreases the influence of talent differences on the RHS of the critical condition (5) and the outside option differences are critical to the type entering the contest.

\footnotetext{
${ }^{14}$ See, for instance, Grossmann and Dietl (2012).
} 
(ii) The critical condition has another counterintuitive implication. Suppose that high types only have a small outside option advantage and low types are much less talented than high types, i.e., $c_{L}>>c_{H}$. In this case, one would expect only high types to enter the contest. However, if the contest noise is sufficiently high, then only low types enter the contest. Therefore, high contest noise attracts the low types. The following corollary sums up the two counterintuitive situations.

Corollary 2 (i) Even if high types have a large outside option advantage $w_{H}>>w_{L}$ and $c_{L}=c_{H}+\epsilon$ for a small value of $\epsilon>0$, only high types enter the contest if the contest noise $\mu$ is sufficiently small, i.e., $\mu<\mu^{*} \equiv 1+\frac{\ln \left(c_{L}\right)-\ln \left(c_{H}\right)}{\ln \left(w_{H}\right)-\ln \left(w_{L}\right)}$.

(ii) Even if low types have a large cost disadvantage $c_{L}>>c_{H}$ and $w_{H}=w_{L}+\epsilon$ for a small value of $\epsilon>0$, only low types enter the contest if the contest noise $\mu$ is sufficiently large, i.e., $\mu>\mu^{*}$.

According to this corollary, a contest organizer should provide a contest with low contest noise to attract high types if he/she is worried about the quality of the types participating in the contest. ${ }^{15}$

\section{Individual and aggregate effort}

Depending on the type of contest, the contest organizer might be interested in maximizing the individual or aggregate effort. In Figures 1a and 1b, we highlight the optimal degree of heterogeneity with respect to the outside option in order to achieve the organizer's preferred objective. Based on the critical condition and its consequences in Propositions (1) and (3), we derive the individual and aggregate efforts of the participating contestants for parameters $V=10, c_{H}=1, c_{L}=1.1, w_{L}=1, \mu=2$. On the x-axis, we vary the high types' value of the outside option $w_{H}$. The critical condition $w_{H} / w_{L}=\left(c_{L} / c_{H}\right)^{\frac{1}{\mu-1}}$ holds for $w_{H}=1.1$ and there is therefore a discontinuity of the individual effort in the contest. ${ }^{16}$

Figure 1a shows that the individual effort is maximized if $w_{H}$ converges to 1.1. The rationale for this result is that a low $w_{H}$ implies that only high types enter the contest but with individually low effort incentives. The effort incentives increase in $w_{H}$, but if $w_{H}>1.1$, then the high types prefer their outside options and only the low types participate in the contest. However, Figure 1a also shows that a contest organizer might prefer to have low types in the contest if the outside option of the high types is low. If $w_{H}$ is smaller than $\sim 0.91$, the individual effort of the high type is smaller than the individual effort exerted by the low types (in the absence of high types). ${ }^{17}$ In accordance with this result, we obtain the following corollary: ${ }^{18}$

Corollary 3 A contest organizer does not necessarily prefer to have high types in the contest in order to maximize the individual effort.

(i) A contest organizer prefers high types with larger values of outside options to low types, but the high types' outside option should not be so attractive that they will not enter the contest.

(ii) However, if the high types' outside option is low, a contest organizer wishes to exclude the high types from the contest and attract the low types instead.

Figure 1b highlights that a contest organizer prefers a low value of the high type's outside option if he/she

\footnotetext{
${ }^{15}$ Note that $\mu^{*}$ is derived from the critical condition (5) solved for $\mu$.

${ }^{16}$ For $w_{H}<1.1$, only high types participate in the contest. For $w_{H}>1.1$, only low types participate in the contest.

${ }^{17}$ For instance, a high type's effort is $x_{H}^{*}(i)=0.71$ for $w_{H}=0.5$ according to Proposition (1) and Figure 1a. In the absence of high types, which holds for instance in the case of $w_{H}=1.4$, then a low type's effort is $x_{L}^{*}(j)=0.95>0.71$, according to Proposition (3) and Figure 1a.

${ }^{18}$ Analyzing Propositions (1) and (3), this corollary holds generally and not only for the specific values used for Figure 1a.
} 
maximizes the aggregate effort. ${ }^{19}$ In this case, a large number of high types participate in the contest, with each participant contributing low effort levels. Therefore, we obtain the following corollary: ${ }^{20}$

Corollary 4 In order to maximize the aggregate effort, a contest organizer prefers high types with low values of the outside option in the contest.

According to Corollaries (3) and (4), we conclude that the optimal degree of heterogeneity with respect to the outside options depends on the organizer's objective.

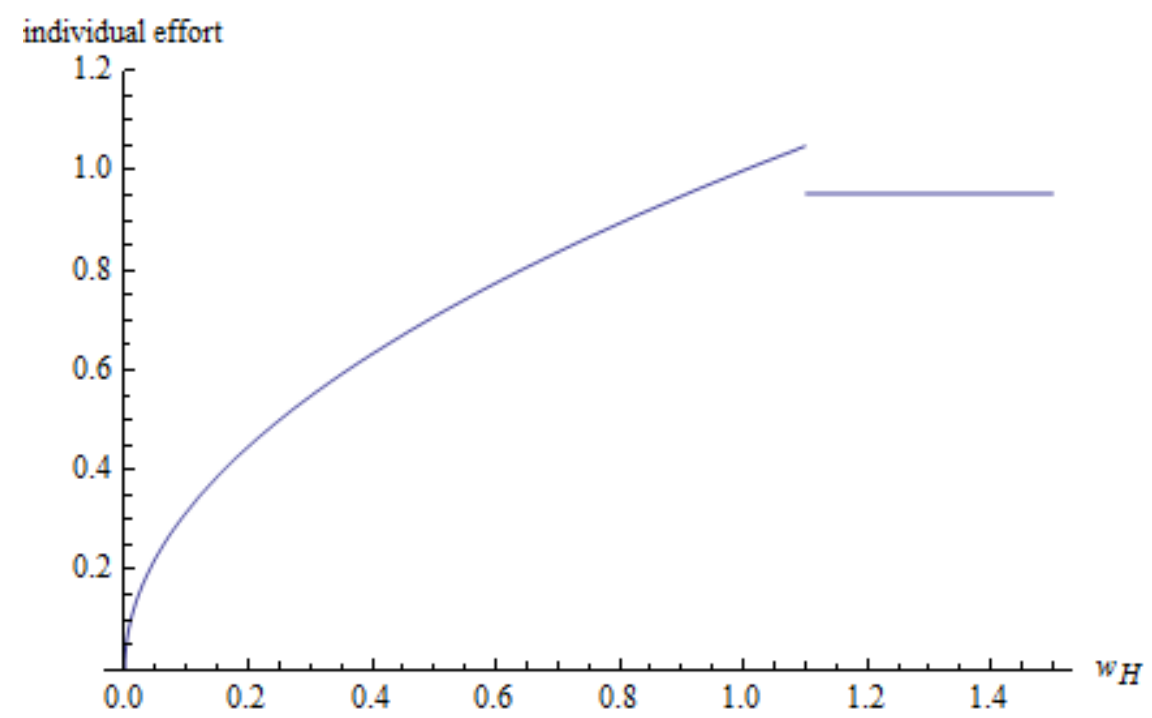

a)

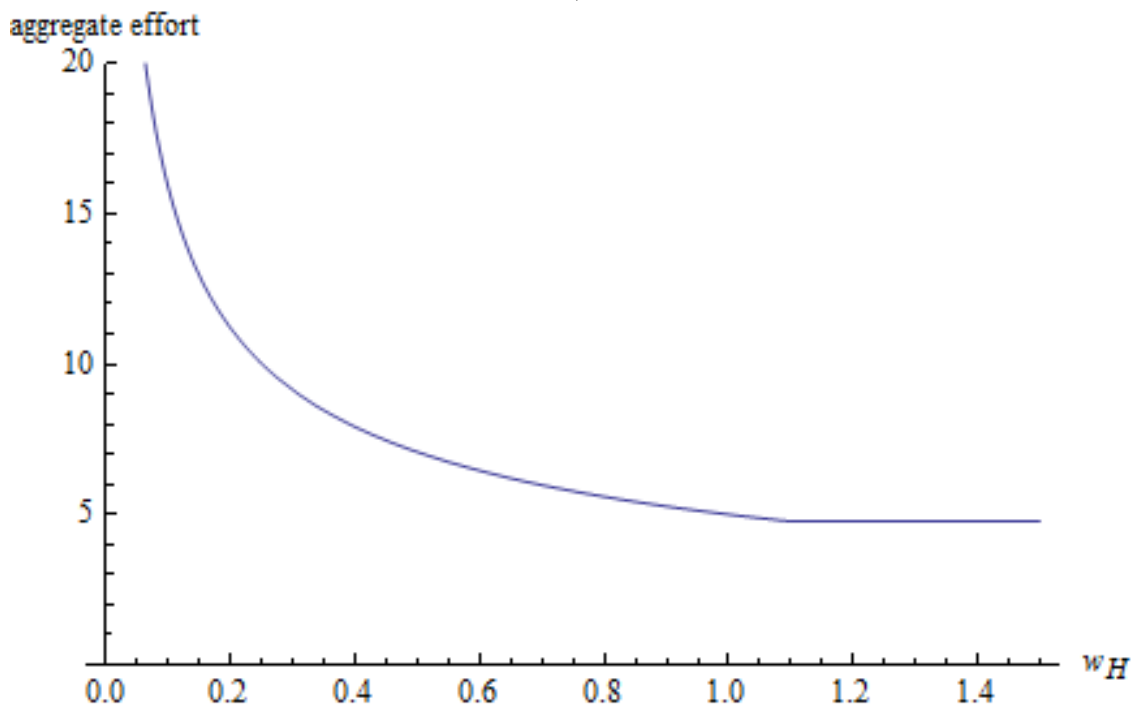

b)

Figure 1: Heterogeneity of outside options and effort

\footnotetext{
${ }^{19}$ Note that for $w_{H}>1.1$, only low types enter the contest. In this case, the aggregate effort is independent of the high type's outside option.

${ }^{20}$ Analyzing Propositions (1) and (3), this corollary holds generally and not only for the specific values used for Figure $1 \mathrm{~b}$.
} 


\section{Conclusion}

This article introduces heterogeneity into a contest with endogenous entry and aggregate-taking behavior. A large number of low- and high-type contestants individually decide whether to enter a contest or choose a heterogenous outside option. We show that only high types enter the contest if the high types' cost advantage is larger than the outside option advantage/disadvantage and the contest noise is small. Otherwise, only low types participate in the contest. A larger contest prize does not influence the individual effort but increases the aggregate effort. Moreover, a greater value of the outside option increases the individual effort but has a negative effect on the aggregate effort. We show that a contest organizer does not necessarily prefer to have high types in the contest in order to maximize the individual effort. The aggregate effort is maximized for a small value of the outside option.

Our framework provides the first step in analyzing the effect of heterogeneous outside options on the selfselection process determining the participation in contests. In particular, the application of aggregate-taking behavior seems to be a promising tool to achieve better tractability of heterogeneity. Other applications and

model extensions should be pursued by further analysis. For instance, the value of the outside options could be endogenously determined in the model.

\section{Acknowledgments}

We would like to thank Andreas Hefti, Reto Föllmi and Markus Lang for helpful comments and suggestions. 


\section{Appendix A}

Suppose that $n$ symmetric contestants participate in a discrete representation of the contest. Then, contestant $i$ 's profit function is

$$
\pi(i)=\frac{x(i)}{X} V-c \cdot x(i)^{\mu}
$$

with $X \equiv \sum_{i=1}^{n} x(i)$ representing the aggregate. Defining $y(i) \equiv x(i)^{\mu}$, we can reformulate the profit function as follows:

$$
\pi(i)=\frac{y(i)^{\frac{1}{\mu}}}{Y} V-c \cdot y(i)
$$

with $Y \equiv \sum_{i=1}^{n} y(i)^{\frac{1}{\mu}}$ representing the aggregate. In this case, contestant $i$ chooses $y(i)$ in order to maximize the expected profit for a given aggregate $Y$ and the parameter $\mu$ reflects the sensitivity of the CSF, i.e., the contest noise, and $c$ represents the constant marginal cost of investment. A higher $\mu$ implies a lower sensitivity of the CSF. ${ }^{21}$

\section{Appendix B}

Suppose that $n$ symmetric contestants participate in a discrete representation of the contest and $\mu=2$. Contestant $i$ 's profit function is

$$
\pi(i)=\frac{x(i)}{X} V-c \cdot x(i)^{2}
$$

with $X=\sum_{i=1}^{n} x(i)$.

ATB equilibrium: With ATB, contestant $i$ maximizes (6) for a given level of the aggregate $X$. Then, the (implicit) reaction function of contestant $i$ is $x(i)=V /(2 c X)$. In a symmetric equilibrium, we obtain

$$
x(i)^{A T B}=\sqrt{\frac{V}{2 c n}}
$$

Nash equilibrium: Contestant $i$ maximizes (6) with respect to $x(i)$ taking into account the effect of $x(i)$ on the aggregate $X$. Then, the (implicit) reaction function of contestant $i$ is $x(i)=\sum_{j \neq i} x(j) V /\left(s c X^{2}\right)$. In a symmetric equilibrium, we obtain

$$
x(i)^{N a s h}=\sqrt{\frac{(n-1) V}{n^{2} s c}}
$$

It is easy to see that $\sqrt{\frac{n-1}{n}} x(i)^{A T B}=x(i)^{N a s h}$ holds and therefore $x(i)^{A T B}>x(i)^{N a s h}$. Thus, contestants invest more in the case of ATB as they neglect their impact on the aggregate. Moreover, the ATB equilibrium converges to the Nash equilibrium if $n$ converges to infinity because $\lim _{n \rightarrow \infty} \sqrt{\frac{n-1}{n}}=1$.

\footnotetext{
${ }^{21}$ See Tullock (1980) or Nitzan (1994).
} 


\section{References}

Alós-Ferrer, C., Ania, A.B., 2005. The evolutionary stability of perfectly competitive behavior. Economic Theory 26, 497-516.

Appelbaum, E., Katz, E., 1986. Rent seeking and entry. Economics Letters 20, 207-212.

Appelbaum, E., Katz, E., 1987. Seeking rents by setting rents: The political economy of rent seeking. Economic Journal 97, 685-699. Reprinted in: Congleton, R.D., Hillman, A.L., Konrad, K.A. (Eds.), 2008. Forty Years of Research on Rent Seeking 1 - Theory of Rent Seeking, Springer, Heidelberg, pp. 555-569.

Chowdhury, S.M., Sheremeta, R.M., 2011. Multiple equilibria in Tullock contests. Economics Letters 112, 216-219.

Corcoran, W.J., 1984. Long-run equilibrium and total expenditures in rent-seeking. Public Choice 43, 89-94. Dari-Mattiacci, G., Langlais, E., Lovat, B., Parisi, F., 2015. Asymmetries in rent seeking. In: Congleton, R.D., Hillman, A.L. (Eds), Companion to Political Economy of Rent Seeking, Edward Elgar, Cheltenham UK and Northampton MA, chapter 5.

Franke, J., 2012. Affirmative action in contest games. European Journal of Political Economy 28, 105-118. Fullerton, R.L., McAfee, R.P., 1999. Auctioning entry into tournaments. Journal of Political Economy 107, 573-605.

Fu, Q., Lu, J., 2010. Contest design and optimal endogenous entry. Economic Inquiry 48, 80-88.

Grossmann, M., Dietl, H., 2012. Asymmetric contests with liquidity constraints. Public Choice 150, 691-713.

Grossmann, M., Hefti, A., Lang, M., 2012. Aggregative contests and ex-post heterogeneity: the case of the Uefa Champions League. Working Paper Series No. 161, Institute for Strategy and Business Economics, Zurich.

Grossmann, M., 2014. Uncertain contest success function. European Journal of Political Economy 33, 134-148.

Hillman, A.L., Katz, E., 1984. Risk-averse rent seekers and the social costs of monopoly power. Economic Journal 94, 104-110. Reprinted in: Congleton, R.D., Hillman, A.L., Konrad, K.A. (Eds.), 2008. Forty Years of Research on Rent Seeking 1 - Theory of Rent Seeking, Springer, Heidelberg, pp. 97-103.

Hillman, A.L., Samet, D., 1987. Dissipation of contestable rents by small numbers of contenders. Public Choice 54, 63-82. Reprinted in: Congleton, R.D., Hillman, A.L., Konrad, K.A. (Eds.), 2008. Forty Years of Research on Rent Seeking 1 - Theory of Rent Seeking, Springer, Heidelberg, pp. 165-184.

Hurley, T.M., Shogren, J.F., 1998. Asymmetric information contests. European Journal of Political Economy $14,645-665$.

Jensen, M.K., 2010. Aggregative games and best-reply potentials. Economic Theory 43, 45-66.

Kräkel, M., 2007. Doping and cheating in contest-like situations. European Journal of Political Economy 23, 988-1006.

Konrad, K.A., 2009. Strategy and Dynamics in Contests. Oxford University Press, Oxford.

Long, N.V., 2013. The theory of contests: A unified model and review of the literature. European Journal of Political Economy 32, 161-181. Reprinted in: Congleton, R.D., Hillman, A.L. (Eds), 2015. Companion to Political Economy of Rent Seeking, Edward Elgar, Cheltenham UK and Northampton MA, chapter 3.

Moldovanu, B., Sela, A., 2001. The optimal allocation of prizes in contests. American Economic Review 91, $542-558$.

Morgan, J., Orzen, H., Sefton, M., 2012. Endogenous entry in contests. Economic Theory 51, 435-463.

Nitzan, S., 1994. Modelling rent-seeking contests. European Journal of Political Economy 10, 41-60.

Nti, K.O., 1999. Rent-seeking with asymmetric valuations. Public Choice 98, 415-430. 
Nti, K.O., 2004. Maximum efforts in contests with asymmetric valuations. European Journal of Political Economy 20, 1059-1066.

Possajennikov, A., 2003. Evolutionary foundations of aggregate-taking behavior. Economic Theory 21, 921-928.

Szymanski, S., Valletti, T.M., 2005. Incentive effects of second prizes. European Journal of Political Economy 21, 467-481.

Tullock, G., 1980. Efficient rent-seeking. In: Buchanan, J.M., Tollison, R.D., Tullock, G. (Eds.), Toward a Theory of Rent Seeking Society. A\&M University Press, College Station, TX, pp. 97-112. Reprinted in: Congleton, R.D., Hillman, A.L., Konrad, K.A. (Eds.), 2008. Forty Years of Research on Rent Seeking 1 Theory of Rent Seeking, Springer, Heidelberg, pp. 105-120. 